\title{
Expression levels of eIF4E, VEGF, and cyclin D1, and correlation of eIF4E with VEGF and cyclin D1 in multi-tumor tissue microarray
}

\author{
SHERRY X. YANG ${ }^{1}$, STEPHEN M. HEWITT ${ }^{2}$, SETH M. STEINBERG ${ }^{3}$, \\ DAVID J. LIEWEHR ${ }^{3}$ and SANDRA M. SWAIN ${ }^{4}$
}

\author{
${ }^{1}$ National Clinical Target Validation Laboratory, Division of Cancer Treatment and Diagnosis; \\ ${ }^{2}$ Laboratory of Pathology, ${ }^{3}$ Biostatistics and Data Management Section, ${ }^{4}$ Medical Oncology Branch, \\ Center for Cancer Research, National Cancer Institute, Bethesda, Maryland 20892, USA
}

Received July 28, 2006; Accepted October 2, 2006

\begin{abstract}
The mRNA cap-binding protein, eukaryotic initiation factor $4 \mathrm{E}$ (eIF4E), is a rate-limiting factor of cap-dependent translation initiation. When elevated, eIF4E greatly facilitates translation of a selected spectrum of mRNAs coding for proteins critical to angiogenesis and growth such as vascular endothelial growth factor (VEGF) and cyclin D1. Expression levels of eIF4E, VEGF, and cyclin D1 were examined in multi-tumor tissue microarray by immunohistochemistry and analyzed quantitatively. eIF4E, VEGF and cyclin D1 protein were elevated in tumors of the breast $(62,78$, or $40 \%)$, colon $(72,77$, or $12 \%)$, glioblastoma multiforme $(48,68$, or $52 \%)$, lymphoma $(66,74$, or $38 \%)$, melanoma $(59,73$, or $58 \%)$, NSCLC $(81,82$, or $29 \%)$, ovary $(50,39$, or $13 \%)$, and prostate $(78,97$, or $21 \%)$, respectively. eIF4E levels were strongly correlated with VEGF and cyclin D1 in melanoma (Spearman's $\mathrm{r}=0.97$ and 0.77 ; all $\mathrm{P}<0.0001$ ); moderately in tumors of the breast $(\mathrm{r}=0.55$ and 0.41 ; all $\mathrm{P}<0.0005)$, colon $(0.63$ and 0.56 ; all $\mathrm{P}<0.0001)$, lung $(0.53$ and 0.53 ; all $\mathrm{P}<0.005)$, lymphoma $(0.50$ and 0.61 ; all $\mathrm{P}<0.0005)$, prostate $(0.46$ and 0.54 ; all $\mathrm{P}<0.005)$, or ovary $(0.56$ and 0.46 ; all $\mathrm{P}<0.005)$; and weakly in tumors of glioblastoma multiforme $(r=0.20$ and 0.31 ; all $\mathrm{P}>0.15)$. The significant association of eIF4E with VEGF and cyclin D1 in multiple tumors supports a role for eIF4E in translational regulation of proteins related to angiogenesis and growth.
\end{abstract}

\section{Introduction}

Translational control is of importance in the regulation of gene expression that primarily occurs at the steps of translation

Correspondence to: Dr Sherry X. Yang, 37 Convent Drive, Bldg. 37/Rm. 1048A, Bethesda, MD 20892, USA

E-mail: yangxia@mail.nih.gov

Key words: cyclin D1, eukaryotic initiation factor 4E, tissue microarray, vascular endothelial growth factor initiation. The mRNA cap-binding protein, eukaryotic initiation factor $4 \mathrm{E}$ (eIF4E) is critical in translation initiation due to its limiting amount in the cell (1). It binds to the $5^{\prime} \mathrm{m} 7 \mathrm{G}$ cap of mRNAs, thereby facilitating eIF4A, an RNA helicase, to unwind the secondary structures at $5^{\prime}$ untranslated region (UTR) until binding of the AUG initiation codon of mRNA to the $40 \mathrm{~S}$ ribosomal subunit (2). When elevated, it preferentially increases translation of mRNAs having long 5'UTRs with more secondary structures rather than those having short 5'UTRs with less secondary structures (3). The latter are efficiently translated in conditions with a normal level of eIF4E. Long and secondary structures at 5'UTR impede eIF4E binding to the mRNA cap in the initiation phase of protein synthesis (4). Gene amplification and/or transcriptional regulation such as hypoxia are the underlying mechanisms that up-regulate eIF4E in human solid tumors (5).

The mRNAs coding for vascular endothelial growth factor (VEGF) and cyclin D1 have long or structured 5'UTRs that are subjected to translational regulation by eIF4E. VEGF, also referred to as VEGF A, is a potent, selective endothelial cell growth factor expressed in a wide spectrum of human tumors (6). It consists of 5 isoforms $\left(\mathrm{VEGF}_{121,145,165,189 \text { and 206 }}\right)$ that have $121,145,165,189$, and 206 amino acids, respectively, among which $\mathrm{VEGF}_{165}$ is the major isoform secreted despite a significant fraction still bound on the cell surface and extracellular matrix (7). In vitro, cells transfected with eIF4E showed a marked increase of VEGF protein secretion that stimulates the growth of human umbilical vein endothelial (HUVEC) cells (8). In vivo, eIF4E has been shown to be associated with VEGF expression in tumors of the bladder (9). Cyclin D1 is a G1 to S cell cycle transit cyclin. Aberrant elevation of cyclin D1 has been detected in malignancies of diverse origins that are attributed to gene amplification, aberrant transcriptional or translational regulation. The protein but not its transcript is elevated in NIH3T3 cells when transfected with eIF4E (10). The increase is in part due to translation initiation (11). In colon adenomas and carcinomas the elevated eIF4E has been associated with cyclin D1 expression (12).

Over expression of eIF4E in NIH3T3 cells or direct microinjection of the protein into these cells led to a 
transformed phenotype $(13,14)$. It is over expressed in cultured cancer cell lines (15) and in tumors of the breast, bladder, colon, head and neck, lymphoma, lung, and thyroid $(9,12$, 16-21). It has a higher expression rate in breast tumor than in normal breast (22). By semi-quantitative Western blotting, eIF4E has been shown to be several-fold higher in adenocarcinoma of the lung compared to normal lung tissues (19). However, to date expression of eIF4E and its potential regulation of VEGF and cyclin D1 have not been assessed in a simultaneous and comprehensive fashion in multiple tumors and normal tissues by immunohistochemistry quantitatively.

Tissue microarray technology provides a tool for high throughput screening of multiple tissues. The National Cancer Institute has, therefore, developed a series of multi-tumor tissue microarrays (tissue array research program, TARP) to expedite discovery of novel targets important in cancer treatment. Thus, in this study the protein expression of eIF4E, VEGF and cyclin D1 was examined in TARP tissue microarray by immunohistochemistry and analyzed quantitatively with an automated digital imaging system. The expression spectrums of eIF4E, VEGF and cyclin D1 between tumors and normal tissues were compared, and potential relationships of eIF4E with VEGF and cyclin D1 expression by tumor type were explored.

\section{Materials and methods}

TARP tissue microarray. TARP array consists of 500 anonymized tumor and normal tissue cores, including 75 representative tumors of breast, colon, prostate, and nonsmall cell lung cancer (NSCLC), respectively; 50 tumors of ovarian cancer, lymphoma, and normal tissues of different origins, respectively; and 25 each of glioblastoma multiforme (GBM) and melanoma. Limited and incomplete clinical information is associated with the tissues used in the construction of the microarray. However, histologic type data for breast, lung or ovarian cancer are available. For more information about TARP, please refer to www.cancer.gov/ $\operatorname{tarp} /$.

Antibodies and immunohistochemistry. Mouse monoclonal antibodies against eIF4E, clone 87 (23) and cyclin D1, clone DCS6 (24) were purchased from Transduction Laboratories (Lexington, KY), and Zymed Laboratories Inc. (S. San Francisco, CA). Goat anti-human neutralizing VEGF polyclonal antibodies (isoforms $\mathrm{VEGF}_{165^{-}}$and $\mathrm{VEGF}_{121^{-}}$ specific) were from R\&D Systems (Minneapolis, MN). Immunohistochemistry on formalin-fixed and paraffinembedded sections was performed using a standard $\mathrm{ABC}$ indirect immuno-peroxidase procedure as described previously (25-27). In brief, following deparaffinization and re-hydration of the microarray sections, antigen retrieval was performed for eIF4E and VEGF in $10 \mathrm{mM}$ Tris- $\mathrm{HCl}$ buffer, $\mathrm{pH} 8.0$, and for cyclin D1 in antigen retrieval buffer, $\mathrm{pH} 6.0$ (Dako Corp., Carpinteria, CA) at $95^{\circ} \mathrm{C}$ in a water bath for 30 min. Subsequently, they were treated with $1 \%$ hydrogen peroxide for $10 \mathrm{~min}$ to inactivate the endogenous peroxidase activity. Primary antibodies (at a dilution of 1:100 for eIF4E; 1:50 for VEGF; 1:10 for cyclin D1) were then applied to the sections at room temperature for $1 \mathrm{~h}$. Binding of antibodies to their antigenic sites in tissue was amplified with $\mathrm{ABC}$ kits (Vector Laboratories, Burlingame, CA). Immuno-reaction sites were revealed by color development using 3, 3'diaminobenzidine for $\sim 5 \mathrm{~min}$ (Sigma, St. Louis, MO). Sections were counterstained with hematoxylin. Immunohistochemical staining was performed in sequential sections of one tissue microarray block. Negative controls were performed using isotype immunoglobulins appropriate to the primary antibodies used (Zymed Laboratories). Optimal antibody concentrations used in the staining procedure were obtained by titration of each antibody on deep-cut sections of the same array.

ACIS-assisted quantitative scoring of tissue microarrays. An automated cellular imaging system (ACIS; ChromaVision Medical Systems, Inc, San Juan Capistrano, CA) was used to quantify immunohistochemical staining (28). Stained slides were scanned by the ACIS, and a mesh grid was then superimposed on the reconstructed tissue core image to compartmentalize each core. When each of them was accurately positioned, a drawing tool was used to define the portion of the core that was tumor or tissue of interest. Then, the quantitative score of staining intensity for each region of interest was calculated by the system computer, and the data was exported to the spreadsheet for analyses. The intensities scored on a continuous scale ranged from 52 to 142 for eIF4E, from 58 to 149 for VEGF and from 55 to 136 for cyclin D1. To validate the scores generated by ACIS and to establish thresholds (cutoff values for elevated expression) for each marker, two observers reviewed the staining both by inspection of the images gathered from the instrument, and by direct observation under a microscope (SY and SH). The thresholds established were 71 for eIF4E, 80 for VEGF, and 81 for cyclin D1.

Statistical analysis. For each of the markers examined, established thresholds were used as the cutoffs to report the elevated expression (percentage) by tumor type. The following analyses were carried out using the whole ranges of data generated with the ACIS. The Wilcoxon rank sum test was used to compare the difference in expression levels of eIF4E as well as VEGF and cyclin D1 between normal tissues and tumors. This was done using the combined data set of multiple tumors and the combined data set of normal tissues in which $10 \%$ or more of tissue or tumor are present. For comparison between each tumor type and the combined normal tissues with each marker, because of the numerous comparisons performed, a two-tailed P-value $<0.01$ was considered as being statistically significant. The differences in eIF4E between squamous cell carcinoma and adenocarcinoma of the lung, and between infiltrating ductal and lobular carcinomas of the breast were also determined with the Wilcoxon rank sum test. An exact Kruskal-Wallis test was used for simultaneous comparisons of eIF4E among mucinous, serous and endometroid carcinomas of the ovary. Spearman's rank correlation coefficient was used to report the association of eIF4E with VEGF or cyclin D1 by tumor type. The strength of association was interpreted to be strong if $|r|>0.7$, moderate if $0.5<|\mathrm{r}|<0.7$, weak to moderate if $0.3<|\mathrm{r}|<0.5$, and weak if $|\mathrm{r}|<0.3$. Except as noted above, in relation to results from 
A. eIF4E

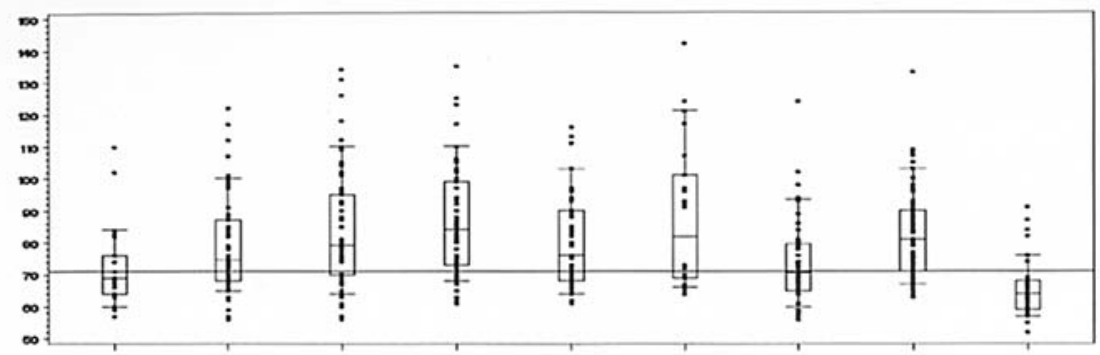

B. VEGF

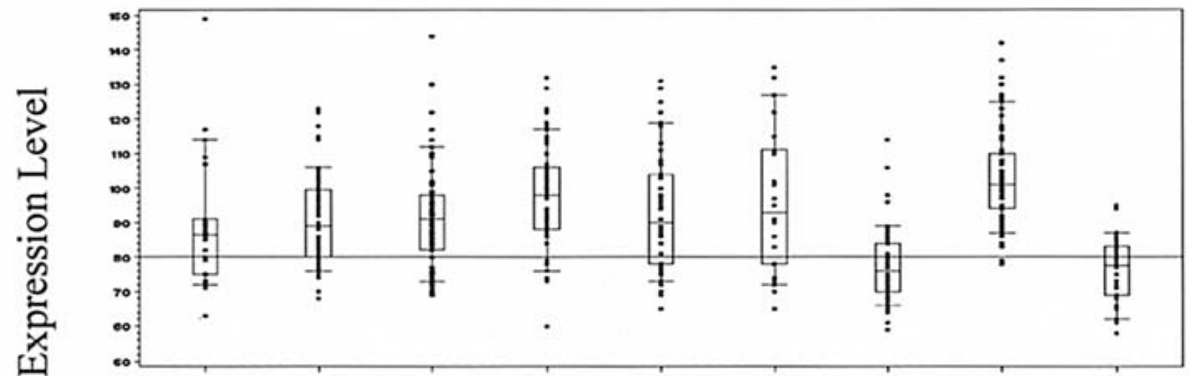

C. Cyclin D1

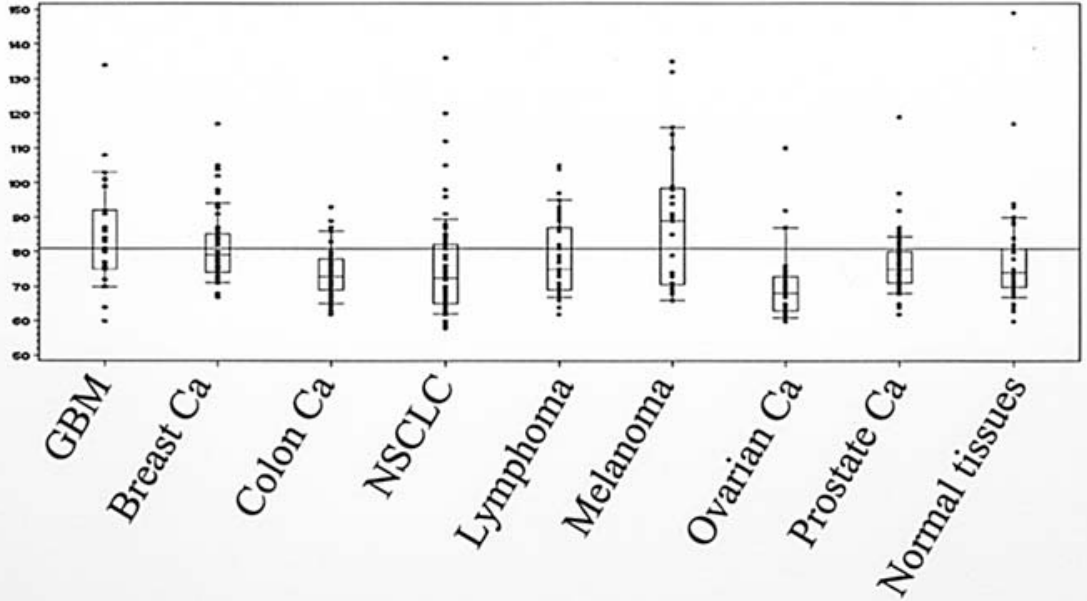

Tumor or Tissue Type

Figure 1. The expression profiles and levels of eIF4E (A), VEGF (B), and cyclin D1 (C) in multiple tumors (or normal tissues). They are shown in corresponding box- and whisker-plots, by tumor type (or normal tissues). Each dot represents the marker expression level determined by quantitative immunohistochemistry in a tumor or tissue core (raw data). Data are summarized as median, the 75 th and 25 th percentiles, and the 90 th and 10 th percentiles (horizontal line within each box, the top and bottom of the box, and the top and bottom of whiskers, respectively). Horizontal lines in A, B, and C are the threshold cut offs.

individual tumor types, all P-values are presented as results from two-tailed tests, unadjusted for multiple comparisons, and considered to be statistically significant if $\mathrm{P}<0.05$.

\section{Results}

Expression profiles of eIF4E, VEGF and cyclin D1 in multitumor tissue microarray. To examine the expression of eIF4E in multiple tumors, we performed immunohistochemistry in the TARP tissue microarray. eIF4E was elevated in tumors of the breast $(42 / 68,62 \%)$, colon $(44 / 61,72 \%)$, GBM $(11 / 23$, $48 \%)$, lung $(51 / 63,81 \%)$, lymphoma $(31 / 47,66 \%)$, melanoma $(13 / 22,59 \%)$, prostate $(54 / 69,78 \%)$, or ovary $(20 / 40,50 \%)$. The most frequent elevation was seen in NSCLC, followed by the prostate, colon, lymphoma, breast, melanoma, ovary, and GBM. Fig. 1A shows the profile of eIF4E in the 8 types of tumor and normal tissues. The level of expression in 393 tumors was significantly higher than that of 43 normal tissues (median; range, 78; 56-142 vs. 64; 52-91; $\mathrm{P}<0.0001$; Table I). A similar pattern was obtained for each of the 8 tumor types when compared to normal tissues (data not shown). Table II lists the fraction with elevation of eIF4E in normal tissues examined. Further, eIF4E levels in infiltrating ductal carcinoma were significantly higher than lobular carcinoma in the breast $(\mathrm{P}=0.007)$. However, there was no significant difference between squamous cell carcinoma and adenocarcinoma of the lung $(\mathrm{P}=0.44)$; nor was there any significant difference among mucinous, serous and endometrial carcinoma of the ovary ( $\mathrm{P}=0.85$; Table III). The levels of eIF4E expression varied from one tumor to another within a tumor type; for 
Table I. eIF4E, VEGF and cyclin D1 in tumors and normal tissues.

\begin{tabular}{lccc}
\hline Marker & $\begin{array}{c}\text { Normal tissues } \\
\text { median (range) }\end{array}$ & $\begin{array}{c}\text { Tumors } \\
\text { median (range) }\end{array}$ & P-value \\
\hline eIF4E & $64(52-91)^{\mathrm{b}}$ & $78(56-142)^{\mathrm{c}}$ & $<0.0001$ \\
VEGF & $78(58-95)^{\mathrm{b}}$ & $91(59-149)^{\mathrm{c}}$ & $<0.0001$ \\
Cyclin D1 & $74(60-149)^{\mathrm{b}}$ & $75(58-136)^{\mathrm{c}}$ & 0.90 \\
\hline
\end{tabular}

${ }^{a}$ Wilcoxon rank sum test, ${ }^{b} \mathrm{n}=43$ for eIF4E and cyclin D1, and 42 for VEGF, ${ }^{c}$ =393 for eIF4E, 401 for VEGF, and 405 for cyclin D1.

Table II. Elevation of eIF4E in normal tissues.

\begin{tabular}{|c|c|}
\hline Tissue type (no.) & $\%$ \\
\hline Mesothelium (2) & 100 \\
\hline Pancreas (1) & 100 \\
\hline Thyroid (1) & 100 \\
\hline Uterus (2) & 100 \\
\hline Liver (2) & 50 \\
\hline Spleen (2) & 50 \\
\hline Lung (3) & 33 \\
\hline Adrenal (2) & 0 \\
\hline Bladder (2) & 0 \\
\hline Bone marrow (1) & 0 \\
\hline Cerebellum (1) & 0 \\
\hline Cerebrum (2) & 0 \\
\hline Colon (2) & 0 \\
\hline Esophagus (2) & 0 \\
\hline Heart (1) & 0 \\
\hline Kidney (1) & 0 \\
\hline Lymph node (2) & 0 \\
\hline Muscle (1) & 0 \\
\hline Ovary (2) & 0 \\
\hline Peripheral nerve (1) & 0 \\
\hline Placenta (1) & 0 \\
\hline Prostate (2) & 0 \\
\hline Salivary gland (1) & 0 \\
\hline Skin (1) & 0 \\
\hline Small intestine (2) & 0 \\
\hline Stomach (1) & 0 \\
\hline Testis (1) & 0 \\
\hline Tongue (1) & 0 \\
\hline
\end{tabular}

instance, in breast tumors it was barely detectable in (A), low in (B), moderate in (C) or high in (D) (Fig. 2).

Expression of VEGF and cyclin D1 was also examined in TARP tissue microarray. Fig. 1B shows the expression profile of VEGF in the 8 types of tumor and normal tissues. It was
Table III. Levels of expression of eIF4E according to histologic types.

\begin{tabular}{lcc}
\hline Histologic type (no.) & Median (range) & P-value \\
\hline $\begin{array}{l}\text { Breast Cancer } \\
\text { Ductal (55) }\end{array}$ & $0.007^{\mathrm{a}}$ \\
Lobular (9) & $76(56-122)$ & \\
NSCLC & $67(63-78)$ & \\
Squamous (29) & $88(67-135)$ & $0.44^{\mathrm{b}}$ \\
Adeno (23) & $83(62-125)$ & \\
Ovarian Cancer & & $0.85^{\mathrm{c}}$ \\
Serous (25) & $71(56-102)$ & \\
Mucinous (2) & $93(61-124)$ & \\
Endometroid (5) & $76(59-98)$ & \\
\hline
\end{tabular}

${ }^{\mathrm{a}}$ Exact Wilcoxon rank sum test, ${ }^{\mathrm{b}} \mathrm{Wilcoxon}$ rank sum test, ${ }^{\mathrm{c} e x a c t}$ Kruskal-Wallis test.

expressed most frequently in tumors of the prostate (97\%), followed by NSCLC (82\%), breast (78\%), colon (77\%), lymphoma (74\%), melanoma (73\%), GBM (68\%), and seen least in tumors of the ovary (39\%). Expression of VEGF in 401 tumors was significantly higher than that of 42 normal tissues $(\mathrm{P}<0.0001$; Table I). Fig. 1C presents the expression profile of cyclin D1. The largest fraction of specimens with elevated expression was in melanoma (58\%), followed by GBM $(52 \%)$, breast cancer $(40 \%)$, lymphoma (38\%), NSCLC $(29 \%)$, and prostate $(21 \%)$, ovarian $(13 \%)$ and colon cancer $(12 \%)$. There was no significant difference between the combined tumors and combined normal tissues, respectively $(\mathrm{P}=0.90$; Table I). However, there was significant difference in cyclin D1 between the combined normal tissues and breast cancer $(\mathrm{P}=0.006)$ and ovarian cancer $(\mathrm{P}=0.0002)$, with trends toward significance for comparisons between normal tissues and $\operatorname{GBM}(\mathrm{P}=0.022)$ and melanoma $(\mathrm{P}=0.032)$.

Correlation of eIF4E with VEGF and cyclin D1 expression. Since eIF4E has a role in the translational regulation of VEGF and cyclin D1 expression, we next performed a rank correlation analysis of eIF4E with VEGF and cyclin D1, by tumor type, to explore the potential association in vivo. As shown in Table IV, eIF4E was strongly associated with VEGF and cyclin D1 proteins in melanoma ( $r=0.97$ and 0.77 , respectively). Moderate or moderate to weak correlation in tumors of breast, colon, lymphoma, NSCLC, prostate and ovary as well as weak correlation in GBM are also presented in Table IV. There was no significant association between eIF4E and a non- eIF4E regulated protein, P-glycoprotein, in any tumor type (data not shown).

\section{Discussion}

The high throughput multi-tumor tissue microarray and quantitative imaging technologies were used in profiling a critical translation initiator eIF4E, an important angiogenic 


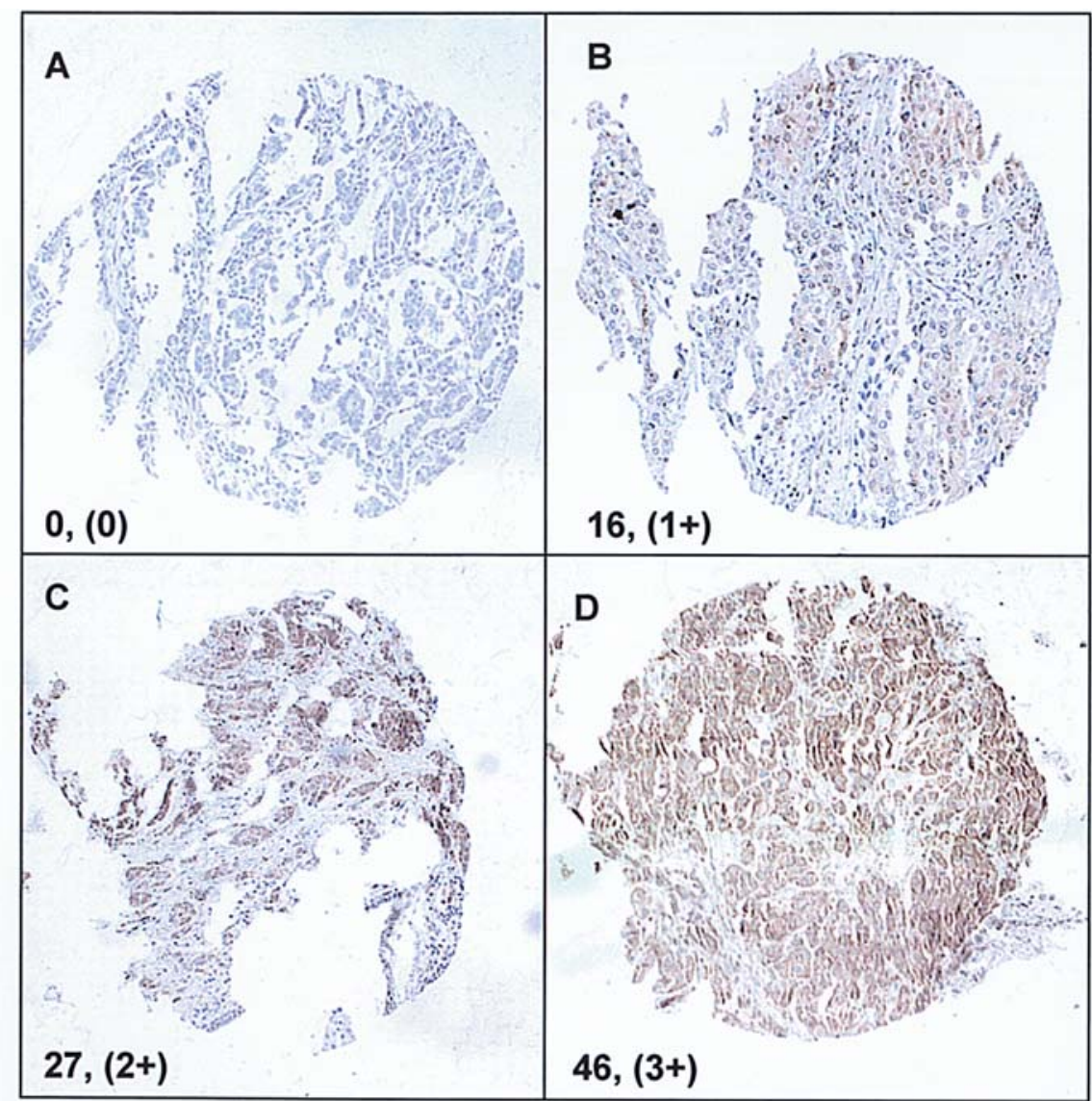

Figure 2. Immunohistochemical analysis of eIF4E in tissue cores of breast cancer. A, B, C or D. Shown are the representative stained tissue cores. The intensities presented are the read-outs by ACIS subtracting 71 (established threshold for eIF4E), and the corresponding numbers in parentheses are manually scored intensities that serve as comparison with the ACIS scores. Any values $\leq 71$ are arbitrarily written as zero. Magnification, $\mathrm{x} 100$.

Table IV. Spearman rank correlation of eIF4E with VEGF and cyclin D1 expression in tumors.

\begin{tabular}{lccccc}
\hline & \multicolumn{2}{c}{ VEGF } & & \multicolumn{2}{c}{ Cyclin D1 } \\
\cline { 2 - 3 } \cline { 5 - 6 } Tumor type & $\mathrm{r}^{\mathrm{a}}$ & $\mathrm{P}^{\mathrm{b}}$ & & $\mathrm{r}$ & $\mathrm{P}$ \\
\hline Breast & 0.55 & $<0.0001$ & & 0.41 & 0.0005 \\
Colon & 0.63 & $<0.0001$ & & 0.56 & $<0.0001$ \\
GBM & 0.20 & 0.39 & & 0.31 & 0.18 \\
NSCLC & 0.53 & $<0.0001$ & & 0.53 & $<0.0001$ \\
Lymphoma & 0.50 & 0.0004 & & 0.61 & $<0.0001$ \\
Melanoma & 0.97 & $<0.0001$ & & 0.77 & $<0.0001$ \\
Ovary & 0.56 & 0.0002 & & 0.46 & 0.0041 \\
Prostate & 0.46 & $<0.0001$ & & 0.54 & $<0.0001$ \\
\hline
\end{tabular}

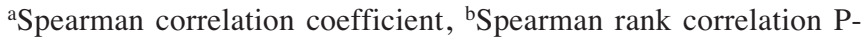
value for test of $\mathrm{r}=0$.

factor VEGF, and a critical cell cycle regulator cyclin D1 in this study. Elevated expression of eIF4E is seen in tumors of all 8 types and to a lesser degree in some normal tissues. It is found for the first time in GBM, melanoma, and ovarian and prostate cancer, indicating that this translation initiator may have more prevalently altered in malignancies than previously thought. In general, expression levels of this factor in tumors are higher than in normal tissues. This is in agreement with the previous data although it is unclear whether eIF4E is a causal factor or a consequence of tumorigenesis. Probably, the increased protein synthesis facilitated by eIF4E is needed for the increased proliferation of malignant cells. However, for those tumors without elevated eIF4E, other mechanisms of translational control at steps of translation initiation may operate to increase protein synthesis. The increased activity and availability of eIF4E, and up-regulation of another translation initiator, such as eIF2 $\alpha$, may occur. Increased eIF2 $\alpha$ has been detected in adenocarcinoma of the lung (23). Growth factors and various cellular stresses via the MAPK /Mnk1/2 pathway phosphorylate eIF4E to increase its activity (29) or through PI3K/Akt/mTOR signaling cascade phosphorylate the $4 \mathrm{E}$-binding protein to release eIF4E to increase its availability (30). In normal tissues examined, those with higher levels of eIF4E were thyroid, pancreas, uterus, and some liver, lung and spleen tissues. These are organs that have high metabolic rates, thus perhaps requiring more eIF4E in protein synthesis. The levels, however, are far less than those seen in tumors.

The significantly higher levels of eIF4E in infiltrating ductal compared to lobular carcinoma of the breast suggest that the former may frequently use the eIF4E mechanism to increase its protein synthesis and lobular carcinoma may primarily utilize other mechanisms. However, the lack of significant 
difference between the squamous and adenocarcinoma of the lung, and serous, mucinous and endometriod carcinoma of the ovary suggests that alteration of eIF4E is similar in all of the histologic subtypes in tumors of the lung and ovary $(19,23)$. Of note, since limited clinical data is available for tissues in the array, it has not been determined whether eIF4E is associated with tumor aggressiveness or progression.

As the most potent endothelial growth factor, VEGF expression levels are significantly higher in multiple tumors than normal tissues, consistent with the concept that tumors are more angiogenic (31). Our data confirms the previous findings that prostate cancer is highly angiogenic as demonstrated by the frequent expression of VEGF (32). These data also implicate that eIF4E may have a role, at least in part, in the regulation of VEGF expression in prostate cancer. Also, VEGF expression is less frequent in ovarian cancer. This may have partly explained why distant metastases are unusual at presentation and during the progression course of ovarian carcinoma (33).

We also profiled cyclin D1 in the 8 types of tumor and normal tissues. In general cyclin D1 elevation frequencies in multiple tumors are similar to the previous results in literature. For example, cyclin D1 protein is reportedly overexpressed in $30-50 \%$ of human breast cancers although the cyclin D1 gene, CCND1, is amplified only in 15\% (34). This suggests that mechanisms in addition to DNA amplification may be implicated in the deregulated expression of cyclin D1 in breast cancer. In this study, the elevated cyclin D1 protein was detected in $40 \%$ of breast cancer cases. In addition, eIF4E levels were moderately to weakly associated with the cyclin D1 levels, suggesting that the translational regulation via eIF4E partly accounted for the deregulation of cyclin D1 in breast cancer. Further, cyclin D1 is more frequently detected in the malignant breast than in the combined normal tissues.

There is an association between levels of eIF4E and VEGF expression and between eIF4E and cyclin D1 in most tumor types. Given the strong association of eIF4E with VEGF and cyclin D1 expression in melanoma, it is likely that eIF4E plays a main or important role in the regulation of VEGF or cyclin D1 expression. The weak association between eIF4E and the two in GBM suggests that it has a minor role in the regulation of VEGF and cyclin D1 expression. Furthermore, in tumors of the breast, colon, lung, lymphoma, ovary and prostate, the moderate or moderate to weak association may indicate a role of eIF4E in the regulation of VEGF and cyclin D1 expression despite a rather complex regulation network involved. Similar to the previous findings, our data found a moderate correlation between eIF4E and cyclin D1 in colon cancer (12). However, there was no association between eIF4E and the non-eIF4E regulated protein, P-glycoprotein. These suggest that this translation initiator has its presumed or specific role in the regulation of proteins such as VEGF and cyclin D1.

To date analysis of eIF4E in human cancer is still limited. Our present findings demonstrate the expression levels of this translation initiator as well as VEGF and cyclin D1 in 8 types of common cancer. Multi-tumor tissue microarray has provided a platform to fast screen markers or targets important in cancer. The automated cellular imaging technology has facilitated the screening process by quantifying proteins in tissues. The correlation of eIF4E with VEGF and cyclin D1 expression in the 8 types of tumor suggests that the translational regulation via eIF4E is important in malignancy.

\section{References}

1. Hiremath LS, Webb NR and Rhoads RE: Immunological detection of the messenger RNA cap-binding protein. J Biol Chem 260: 7843-7849, 1985 .

2. Pestova TV, Kolupaeva VG, Lomakin IB, Pilipenko EV, Shatsky IN, Agol VI and Hellen CU: Molecular mechanisms of translation initiation in eukaryotes. Proc Natl Acad Sci USA 98: 7029-7036, 2001

3. Kozak M: The scanning model for translation: an update. J Cell Biol 108: 229-241, 1989.

4. Koromilas AE, Lazaris-Karatzas A and Sonenberg N: mRNAs containing extensive secondary structure in their 5 ' non-coding region translate efficiently in cells overexpressing initiation factor eIF-4E. EMBO J 11: 4153-4158, 1992.

5. Sorrells DL, Black DR, Meschonat C, Rhoads R, De Benedetti A, Gao M, Williams BJ and Li BD: Detection of eIF4E gene amplification in breast cancer by competitive PCR. Ann Surg Oncol 5: 232-237, 1998.

6. Dvorak HF: Vascular permeability factor/vascular endothelial growth factor: a critical cytokine in tumor angiogenesis and a potential target for diagnosis and therapy. J Clin Oncol 20: 4368-4380, 2002.

7. Ferrara N, Houck K, Jakeman L and Leung DW: Molecular and biological properties of the vascular endothelial growth factor family of proteins. Endocr Rev 13: 18-32, 1992.

8. Kevil CG, De Benedetti A, Payne DK, Coe LL, Laroux FS and Alexander JS: Translational regulation of vascular permeability factor by eukaryotic initiation factor 4E: implications for tumor angiogenesis. Int J Cancer 65: 785-790, 1996.

9. Crew JP, Fuggle S, Bicknell R, Cranston DW, de Benedetti A and Harris AL: Eukaryotic initiation factor-4E in superficial and muscle invasive bladder cancer and its correlation with vascular endothelial growth factor expression and tumour progression. Br J Cancer 82: 161-166, 2000

10. Rosenwald IB, Lazaris-Karatzas A, Sonenberg N and Schmidt EV: Elevated levels of cyclin D1 protein in response to increased expression of eukaryotic initiation factor 4E. Mol Cell Biol 13: 7358-7363, 1993.

11. Rousseau D, Kaspar R, Rosenwald I, Gehrke L and Sonenberg N: Translation initiation of ornithine decarboxylase and nucleocytoplasmic transport of cyclin D1 mRNA are increased in cells overexpressing eukaryotic initiation factor 4E. Proc Natl Acad Sci USA 93: 1065-1070, 1996.

12. Rosenwald IB, Chen JJ, Wang S, Savas L, London IM and Pullman J: Upregulation of protein synthesis initiation factor eIF-4E is an early event during colon carcinogenesis. Oncogene 18: 2507-2517, 1999

13. Lazaris-Karatzas A, Montine KS and Sonenberg N: Malignant transformation by a eukaryotic initiation factor subunit that binds to mRNA 5' cap. Nature 345: 544-547, 1990.

14. Smith MR, Jaramillo M, Tuazon PT, Traugh JA, Liu YL, Sonenberg N and Kung HF: Modulation of the mitogenic activity of eukaryotic translation initiation factor-4E by protein kinase C. New Biol 3: 601-607, 1991.

15. Anthony B, Carter P and De Benedetti A: Overexpression of the proto-oncogene/translation factor $4 \mathrm{E}$ in breast-carcinoma cell lines. Int J Cancer 65: 858-863, 1996.

16. Byrnes K, White S, Chu Q, Meschonat C, Yu H, Johnson LW, Debenedetti A, Abreo F, Turnage RH, McDonald JC and Li BD: High eIF4E, VEGF, and microvessel density in stage I to III breast cancer. Ann Surg 243: 684-690, 2006.

17. Li BD, McDonald JC, Nassar R and De Benedetti A: Clinical outcome in stage I to III breast carcinoma and eIF4E overexpression. Ann Surg 227: 756-761, 1998.

18. Nathan CA, Amirghahri N, Rice C, Abreo FW, Shi R and Stucker FJ: Molecular analysis of surgical margins in head and neck squamous cell carcinoma patients. Laryngoscope 112: 2129-2140, 2002.

19. Seki N, Takasu T, Mandai K, Nakata M, Saeki H, Heike Y, Takata I, Segawa Y, Hanafusa T and Eguchi K: Expression of eukaryotic initiation factor $4 \mathrm{E}$ in atypical adenomatous hyperplasia and adenocarcinoma of the human peripheral lung. Clin Cancer Res 8: 3046-3053, 2002. 
20. Wang S, Lloyd RV, Hutzler MJ, Rosenwald IB, Safran MS, Patwardhan NA and Khan A: Expression of eukaryotic translation initiation factors $4 \mathrm{E}$ and 2alpha correlates with the progression of thyroid carcinoma. Thyroid 11: 1101-1107, 2001.

21. Wang S, Rosenwald IB, Hutzler MJ, Pihan GA, Savas L, Chen JJ and Woda BA: Expression of the eukaryotic translation initiation factors 4E and 2alpha in non-Hodgkin's lymphomas. Am J Pathol 155: 247-255, 1999.

22. Nathan CA, Carter P, Liu L, Li BD, Abreo F, Tudor A, Zimmer SG and De Benedetti A: Elevated expression of eIF4E and FGF-2 isoforms during vascularization of breast carcinomas. Oncogene 15: 1087-1094, 1997.

23. Rosenwald IB, Hutzler MJ, Wang S, Savas L and Fraire AE: Expression of eukaryotic translation initiation factors $4 \mathrm{E}$ and 2alpha is increased frequently in bronchioloalveolar but not in squamous cell carcinomas of the lung. Cancer 92: 2164-2171, 2001.

24. Sicinski P, Donaher JL, Parker SB, Li T, Fazeli A, Gardner H, Haslam SZ, Bronson RT, Elledge SJ and Weinberg RA: Cyclin D1 provides a link between development and oncogenesis in the retina and breast. Cell 82: 621-630, 1995.

25. Tan AR, Yang X, Hewitt SM, Berman A, Lepper ER, Sparreboom A, Parr AL, Figg WD, Chow C, Steinberg SM, Bacharach SL, Whatley M, Carrasquillo JA, Brahim JS, Ettenberg SA, Lipkowitz S and Swain SM: Evaluation of biologic end points and pharmacokinetics in patients with metastatic breast cancer after treatment with erlotinib, an epidermal growth factor receptor tyrosine kinase inhibitor. J Clin Oncol 22: 3080-3090, 2004.

26. Wedam SB, Low JA, Yang SX, Chow CK, Choyke P, Danforth D, Hewitt SM, Berman A, Steinberg SM, Liewehr DJ, Plehn J, Doshi A, Thomasson D, McCarthy N, Koeppen H, Sherman M, Zujewski J, Camphausen K, Chen $\mathrm{H}$ and Swain SM: Antiangiogenic and antitumor effects of bevacizumab in patients with inflammatory and locally advanced breast cancer. J Clin Oncol 24: 769-777, 2006.
27. McCarthy NJ, Yang X, Linnoila IR, Merino MJ, Hewitt SM, Parr AL, Paik S, Steinberg SM, Hartmann DP, Mourali N, Levine PH and Swain SM: Microvessel density, expression of estrogen receptor alpha, MIB-1, p53, and c-erbB-2 in inflammatory breast cancer. Clin Cancer Res 8: 3857-3862, 2002.

28. Maitra A, Ashfaq R, Gunn CR, Rahman A, Yeo CJ, Sohn TA, Cameron JL, Hruban RH and Wilentz RE: Cyclooxygenase 2 expression in pancreatic adenocarcinoma and pancreatic intraepithelial neoplasia: an immunohistochemical analysis with automated cellular imaging. Am J Clin Pathol 118: 194-201, 2002.

29. Frederickson RM, Montine KS and Sonenberg N: Phosphorylation of eukaryotic translation initiation factor $4 \mathrm{E}$ is increased in Src-transformed cell lines. Mol Cell Biol 11: 2896-2900, 1991

30. Horton LE, Bushell M, Barth-Baus D, Tilleray VJ, Clemens MJ and Hensold JO: p53 activation results in rapid dephosphorylation of the eIF4E-binding protein 4E-BP1, inhibition of ribosomal protein S6 kinase and inhibition of translation initiation. Oncogene 21: 5325-5334, 2002.

31. Folkman J: Role of angiogenesis in tumor growth and metastasis. Semin Oncol 29: 15-18, 2002.

32. Kollermann J and Helpap B: Expression of vascular endothelial growth factor (VEGF) and VEGF receptor Flk-1 in benign, premalignant, and malignant prostate tissue. Am J Clin Pathol 116: 115-121, 2001

33. Cormio G, Rossi C, Cazzolla A, Resta L, Loverro G, Greco P and Selvaggi L: Distant metastases in ovarian carcinoma. Int $\mathrm{J}$ Gynecol Cancer 13: 125-129, 2003.

34. Hosokawa Y and Arnold A: Mechanism of cyclin D1 (CCND1, PRAD1) overexpression in human cancer cells: analysis of allele-specific expression. Genes Chromosomes Cancer 22: 66-71, 1998. 